\title{
An effective stress approach for hydro-mechanical coupling of unsaturated soils
}

\author{
Hiram Arroyo ${ }^{1, a}$, Eduardo Rojas ${ }^{1}$ and José Arroyo ${ }^{2}$ \\ ${ }^{1}$ Faculty of Engineering, Universidad Autónoma de Querétaro, Centro Universitario, Cerro de las campanas, Qro., México \\ ${ }^{2}$ Faculty of Civil Engineering, Universidad Michoacana de San Nicolás de Hidalgo, Centro Universitario, Avenida \\ Francisco J. Mújica S/N, México
}

\begin{abstract}
The simulation of the mechanical and hydraulic behaviour of soils is one of the most important tasks in soil mechanics. It is inaccurate to consider that the behaviour of saturated and unsaturated soils as if their governing laws were utterly different, this last condition is not sufficient to do so. However, unlike the laws governing the behaviour of saturated soils, those used to describe the behaviour of unsaturated soils lack the simplicity and predictability associated to the complexity of the phenomena that occur within these porous media. This is why it is important to establish a unified soil mechanics theory to reconcile saturated and unsaturated soil mechanics. In the present work, we describe a simple analytical equation to obtain effective stresses for any type of soil. The equation is coupled to an elastoplastic constitutive model which is capable to reproduce the stress-strain relationship of soil taking into account the hydro-dynamic coupling.
\end{abstract}

\section{Introduction}

Constitutive models for soils are intended to capture and predict the most important characteristics of their behavior.

On the matter of the Mechanics of Unsaturated Soils, the pioneering work by Alonso et al. [1] based, amongst others, on the work by Roscoe and Burland [2] are central pieces to understand the main trends on current scientific studies.

In this regard, the research stream related to constitutive modelling has paid attention on establishing a unified scheme for saturated and unsaturated behavior. Moreover, a constitutive model that couples both hydraulic and mechanical characteristics amongst a model is of paramount importance.

With this in mind, constitutive models research stream goes through two different ways. The first one concerns to the formulation of equations based on the assumption that the strains induced by suction $s$ and the strains induced by mean net stresses $p_{\text {net }}$ (or deviator stresses $q$ ) have no correlation. This is called, "independent state stress variables formulation".

The second one refers to the formulation of equations based on effective stress concept [3, 4]. These models are based on the "effective" stress concept by Terzaghi [5] for which it is stated that a single stress controls the hydraulic and mechanical behavior of soils. Governing relations formulated in terms of this type of stress are increasingly being used due to several advantages regarding the features they naturally capture for unsaturated soils $[3,4,6]$.

Several constitutive models have been proposed to predict the mechanical behavior of unsaturated soils and more generally, the hydro-mechanical behavior of porous media [3, 6-9]. However, despite most of them are able to reproduce the most important features of these materials, complicated and elaborated laboratory testing procedures are required to determine the parameters contained within their relations.

In this research, an effective stress equation similar to that of Bishop [10] is analytically derived and helps to establish a complete elastoplastic constitutive framework for soils.

The main objective of this research is to propose highly coupled stress-strain-hydraulic relations for unsaturated soils to predict their mechanical behavior under cyclic loading and under any degree of saturation. Moreover, the input parameters for the constitutive model should be computed with simple soil mechanics test procedures, such as Soil-Water Characteristic Curve, saturated triaxial tests and soil classification.

\section{Effective stress equation}

[Rojas [11]] through an analytical analysis of a crosssection of a soil sample that contained saturated, dry and unsaturated fractions, derived Equation (1).

$$
\sigma^{\prime}=\sigma+\left(f^{s}+f^{u} S_{r}^{u}\right) s
$$

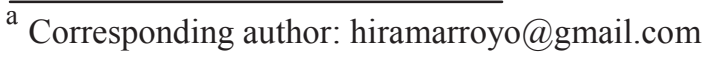


A close-up to Equation (1) verifies that it is actually a Bishop-type equation with $\chi=f^{s}+f^{u} S_{r}^{u}$. Here, $f^{s}$ and $f^{u}$ represent the saturated and unsaturated fractions respectively; $S_{r}^{u}$ stands for the degree of saturation of the unsaturated fraction. The mean effective stress will then be:

$$
p^{\prime}=\frac{\sigma_{1}{ }^{\prime}+2 \sigma_{3}{ }^{\prime}}{3}=p_{n e t}+\left(f^{s}+f^{u} S_{r}^{u}\right) s
$$

Here, $\sigma_{1}{ }^{\prime}$ and $\sigma_{3}{ }^{\prime}$ are the effective stresses applied during a triaxial compression test on the principal directions 1 and 3. $p_{\text {net }}=p-u_{a}$ and $s=u_{a}-u_{w}$ stand for the mean net stress and suction, respectively.

\section{The solid-porous model}

The parameters contained within the parentheses in Equation (2) depend on the distribution of water inside the soil; the way in which their value is computed is described elsewhere $[12,13]$, for the sake of completeness we will roughly describe them herein.

A saturated fraction $f^{s}=V^{s} / V$ is the ratio of saturated volume of soil and the total volume of the soil $V$. A dry fraction $f^{d}=V^{d} / V$ and an unsaturated fraction $f^{u}=V^{u} / V$ are both defined in the same way. The concept of "unsaturated state" is better understood with the aid of Figure 1. Here, a solid particle is surrounded by four sites connected to four bonds, the total of them composing the BU entities. The hatched elements in Figure 1 form a Solid-Porous Unit SPU. The SPU will be part of the "saturated" fraction if all the BU entities are water-filled. If all of them are air-filled, the SPU will be part of the "dry" fraction. With this in mind, the SPU will be part of the "unsaturated" fraction if the BU entities of the SPU are a mixture of water-filled and air-filled entities.

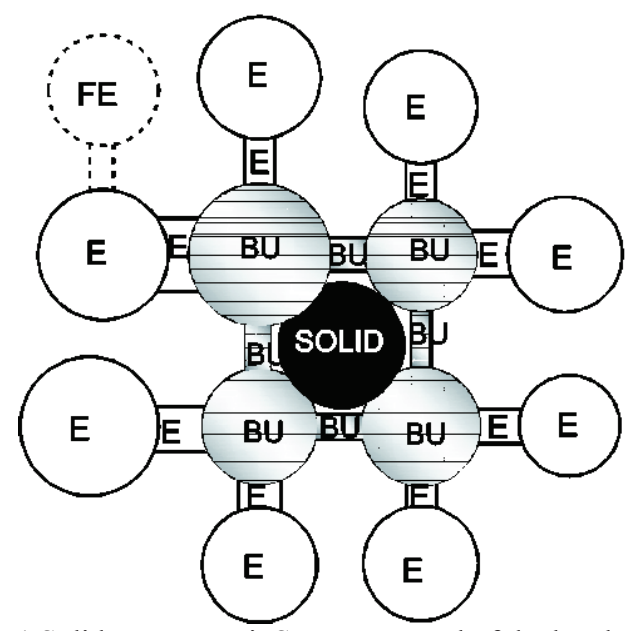

Figure 1 Solid-Porous Unit SPU composed of the hatched BU entities and the solid at the center.

In order to obtain the parameters contained within the parentheses in Equation (2), a Solid-Porous Model (SPM) is proposed. The SPM basically consist of a network of interconnected sites and bonds used to simulate wettingdrying processes. Consider a single site (circular entity) in Figure 1. If it is assumed that the whole volume of the soil is air-filled, suction must appertain a high value according to the Laplace's rule $s=2 T s / R$. If $s$ is increased in steps, with each $\Delta s$ every site of the network is analyzed to see whether it complies with two conditions: 1) its radius must be smaller than the critical value $R c=2 T s / s$, and 2) it must already be connected to a bond that is already water-filled. If the two conditions are met, the site is considered saturated. The total volume of water $V_{w}$ is obtained with every $\Delta s$ by adding all the volumes of the saturated sites. With this procedure, it is possible to simulate a wetting curve and thus plot a Soil Water Characteristic Curve (SWCC) for the soil. Water retention curves are plots in Cartesian space where suction vs. degree of saturation is plotted. The drying process goes in the same way.

The frequency distribution of sites and bonds for the network is obtained taking as a basis its pore-size distribution PSD. The PSD can be obtained either by direct methods from which the intrusion of mercury is one of them, or by fitting the predicted SWCC to the experimental SWCC. This last method can be used to recover the PSD and has proven to be effective [14].

Figure 2 shows a representative part of a porous network composed of solids surrounded by sites. The network is currently at some particular stage of the wetting process as the water proceeds from the lower right corner site $P 12$ through all the bonds and sites. This figure will help to understand and identify the meaning of the variables considered in the effective stress definition.

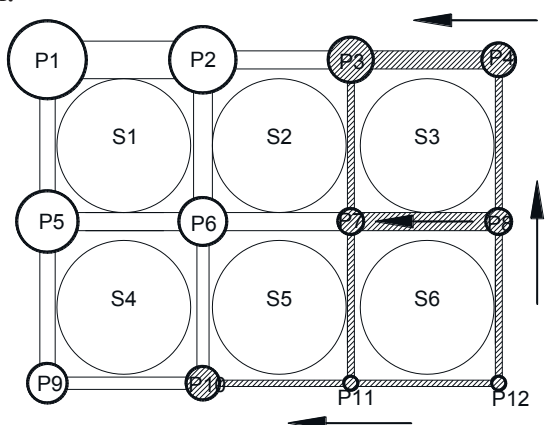

Figure 2 Sketch of the porous structure of a soil in wetting process conditions.

The void volume of the porous network consists of the volume of the sites $P$ and the volume of bonds. Because the contribution of the bonds can be neglected [15], the total volume of the soil $V$ will consist of the volume of solids $V_{S O L}=\sum_{i=1}^{6} S_{i}$ and the volume of sites $V_{S}=\sum_{i=1}^{12} P_{i}$. Accordingly to the previously established definition for the dry fraction, for the porous network in Figure 2, the dry fraction will be obtained by computing $f^{d}=\frac{V^{d}}{V}=\frac{V_{S O L}^{d}}{V}+\frac{V_{S}^{d}}{V}=\frac{S 1}{V}+\frac{P 1+P 2+P 5+P 6}{V}$. Note that, although $P 9$ is air-filled, it is not included to 
compute the dry fraction since it is not a part of any dry or saturated solid.

For the case of the saturated fraction:

$$
\begin{aligned}
f^{s}=\frac{V^{s}}{V}=\frac{V_{S O L}^{S}}{V}+\frac{V_{S}^{S}}{V} & =\frac{(S 3+S 6)}{V} \\
& +\frac{(P 3+P 4+P 7+P 8+P 11+12)}{V}
\end{aligned}
$$

Again, note that although $P 10$ is water-filled, it was not included to compute the saturated fraction since it is not a part of any saturated nor any dry SPU.

The last parameter in equation (2) to be obtained is the degree of saturation of the unsaturated fraction. It is useful to apply the following relationship of void volume $V_{S}^{u}=V_{S}-V_{S}^{S}-V_{S}^{d}=P 9+P 10$; meaning that, neglecting the bonds volume, the void volume is composed of the addition of the void volume of the unsaturated fraction, the void volume of the saturated fraction, and the void volume of the dry fraction, respectively.

Moreover, the volume of water contained within the unsaturated fraction can also be calculated from a simple difference: $V_{w}^{u}=V_{w}-V_{S}^{s}=P 9$; meaning that the total volume of water contained within the porous structure is the addition of the water from the unsaturated fraction and the water from the saturated fraction.

Furthermore, the degree of saturation for the particular stage at which the soli-porous arrangement in Figure 2 is will be $S_{r}^{u}=V_{w}^{u} / V_{S}^{u}=P 9 /(P 9+P 10)$.

Finally, because the $100 \%$ of the soil volume is the addition of the dry, the saturated and the unsaturated fractions, the unsaturated fraction can be obtained with the difference $f^{u}=1-f^{s}-f^{d}$. Now, all the needed elements to compute the effective stress are identified.

Summing up, the previous elements enable obtaining, for every suction step $\Delta s$, the following hydraulic properties of the soil: the Water Retention Curves, the degree of saturation of the unsaturated fraction $S_{r}^{u}$, and the fractions $f^{s}, f^{d}$ and $f^{u}$. All of them depend on the PSD of the material. In order to obtain an analytical equation for the PSD, we propose using a Normal Distribution. This way, parameters for the macroporosity $\left(\mu_{S M}, \sigma_{S M}\right)$ and for the microporosity $\left(\mu_{S m}, \sigma_{S m}\right)$ can be obtained by fitting a Normal Distribution to the Experimental porosimetry as shown in Figure 3.

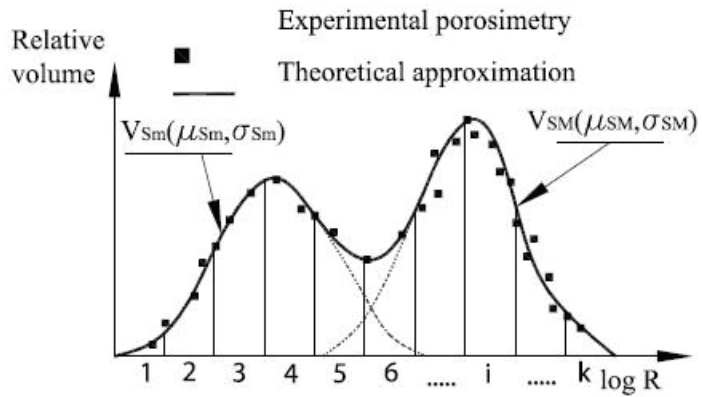

Figure 3 Experimental (black squares) and theoretical (solid line) pore-size distributions.

It has been shown experimentally that the mesopores are the ones that shrink when a soil sample is compressed. With this in mind, the following equation (3) allows obtaining the void ratio for every value that the parameters $\mu_{S M}, \sigma_{S M}, \mu_{S m}$ and $\sigma_{S m}$ take on. Because the basic assumption is that the volume strains are due to the shrinking of the macropores, it will be enough if the mean size of the Normal Distribution for macropores $\mu_{S M}$ is reduced.

$$
\begin{aligned}
& e=e_{M}+e_{m}= \\
& f a \cdot \pi \sum_{i=1}^{k}\left\langle R_{i}^{2} \cdot f_{i}\left(\mu_{S M}, \sigma_{S M}\right) \cdot F p v+R_{i}^{2} \cdot f_{i}\left(\mu_{S m}, \sigma_{S m}\right)\right\rangle= \\
& \quad f a \cdot e_{0}
\end{aligned}
$$

Note that displacing $\mu_{S M}$ towards lower values, reduce the void ratio of the material. This allows linking the mechanical behavior with the SWCC, which is one of the main issues in hydro-mechanical coupling in constitutive modelling. The SPM is completely described elsewhere [13].

\section{Elastoplastic formulation}

\subsection{Yield locus in the $q-p^{\prime}$ stress space}

The mechanical part of the model is formulated under the Elastoplastic theory. The yielding space is composed of a yield locus expressed in terms of deviator stress $q=\sigma_{1}{ }^{\prime}-\sigma_{3}{ }^{\prime}$ and mean effective stress $p^{\prime}$ (see Figure 4) and a yield locus expressed in terms of the suction and the mean effective stress. An associated flow rule is assigned and an ellipse-shaped yield locus is used to identify the yielding in the stress space $q-p^{\prime}$. The hardening parameter controlling the size of the yield function is $p_{0}{ }^{\prime}$. The flow rule is given by Equation (4) proposed Rojas et al. [16]:

$$
d \varepsilon_{v}^{p}=(\lambda-\kappa) \frac{e}{1+e} \frac{d p_{0}{ }^{\prime}}{p_{0}{ }^{\prime}}
$$

Here, $\lambda$ and $\kappa$ are the compressibility indexes for normally consolidated and loading-unloading compression states.

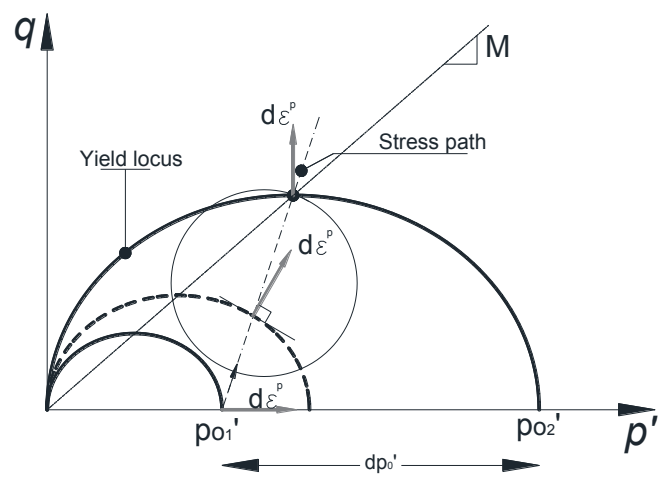

Figure 4 Yield locus for the stress space $q-p$.

The critical state theory is used herein. The plastic deformations are thus expressed with Equation (5). 


$$
\begin{aligned}
& {\left[\begin{array}{l}
d \varepsilon_{v}^{p} \\
d \varepsilon_{d}^{p}
\end{array}\right]=} \\
& -\frac{1}{-M^{2} p^{\prime}\left(p_{0}^{\prime} \frac{(1+e)}{e(\lambda-\kappa)}\right)}\left[\begin{array}{cc}
M^{2}\left(2 p^{\prime}-p_{0^{\prime}}^{\prime}\right) & 2 q \\
2 q & \frac{4 q^{2}}{M^{2}\left(2 p^{\prime}-p_{0}^{\prime}\right)}
\end{array}\right]\left[\begin{array}{c}
d p^{\prime} \\
d q
\end{array}\right]
\end{aligned}
$$

Here, parameter $M=6 \sin \varphi /(3-\sin \varphi)$, where $\varphi$ is the friction angle of the soil; $d \varepsilon_{v}^{p}$ and $d \varepsilon_{d}^{p}$ are the plastic components of the isotropic and deviator strains respectively. The elastic part of the strains is given by

$$
\left[\begin{array}{l}
d \varepsilon_{v}^{p} \\
d \varepsilon_{d}^{p}
\end{array}\right]=\left[\begin{array}{cc}
\kappa & 0 \\
0 & 1 / 3 G
\end{array}\right]\left[\begin{array}{l}
d p^{\prime} \\
d q
\end{array}\right]
$$

Where $G$ represents the shear modulus of the soil.

\subsection{Yield locus in the $s-p^{\prime}$ stress space}

According to Equation (4), when suction increases from a normally consolidated stress state A to stress state $\mathrm{B}, p_{0}{ }^{\prime}$ changes as follows:

$$
\left(d p_{0}\right)_{A-B}=\frac{1+e}{e} \frac{p_{A}^{\prime}}{(\lambda-\kappa)} d \varepsilon_{v}^{p}=d(\chi s)_{A-B}
$$

Therefore, according to Equation (7) an increase in the effective preconsolidation stress $p_{0}{ }^{\prime}$ is as much as $d(\chi s)$. Here, if suction goes from stress state $\mathrm{A}$ to $\mathrm{B}$, the effective preconsolidation stress will increase up to $\left(p_{0}^{\prime}\right)_{A-B}=\left(p_{0}^{\prime}\right)_{A}+\left(d p_{0}^{\prime}\right)_{A-B}=\left(p_{0}^{\prime}\right)_{A}+2 d(\chi s)_{A-B}$. This means that the well-known Loading-Collapse Yield Surface (in reference to Alonso, Gens [1]) appertains the same shape as a drying path (see Figure 5).

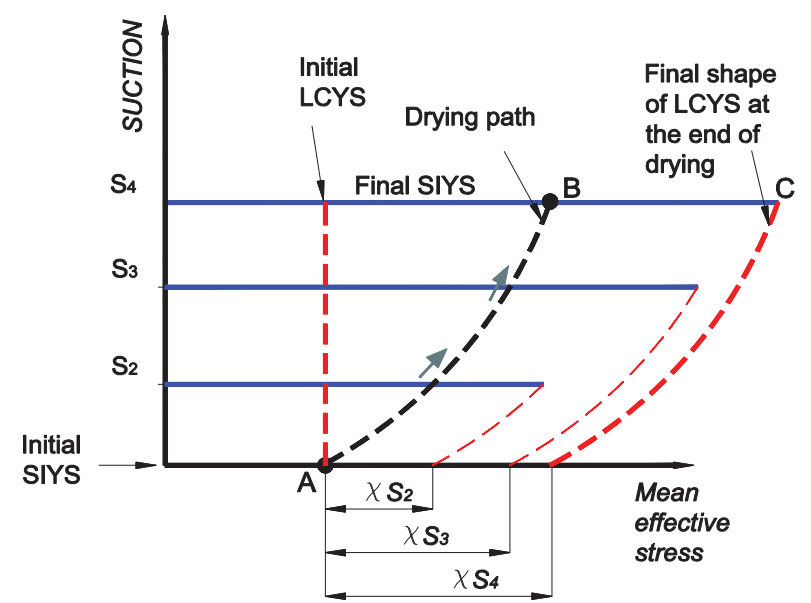

Figure 5 Evolution of yield locus in the $s-p^{\prime}$ stress space

In first instance, here we are considering a SIYS yield surface (Suction Increase Yield Surface) in the same way as Alonso, Gens [1].

According to the outlined elastoplastic framework in Figure 5, at the end of an equalization stage, the soil must be subjected to an additional effective stress $d p_{\text {pnet }}$ in order to reach elastoplastic deformation states. This preconsolidation behavior is experimentally experienced in many reported results. The main idea that need to be highlighted is that the model predicts the effective preconsolidation stress in unsaturated conditions.

\section{Numerical-Experimental comparisons}

The required parameters to predict the shear strength of soils with the proposed model will be the ones depicted in Table 1. It can be noticed that, the required parameters involve tests that can be obtained with classical geotechnical procedures.

Table 1. Input parameters for the proposed model

\begin{tabular}{|c|c|}
\hline Parameter & Geotechnical test \\
\hline $\begin{array}{c}\text { Critical state slope } M \text {, Shearing } \\
\text { Modulus } G \text {, preconsolidation } \\
\text { stress }\left(p_{0}{ }^{\prime}\right)_{0}\end{array}$ & $\begin{array}{c}\text { Drained saturated } \\
\text { triaxial test }\end{array}$ \\
\hline Initial void ratio $e$ & Soil classification \\
\hline Pore-Size Distribution & Water Retention Curve \\
\hline $\begin{array}{c}\text { Compressibility indexes } \lambda \text { and } \\
\kappa\end{array}$ & $\begin{array}{c}\text { Isotropic compression } \\
\text { test }\end{array}$ \\
\hline
\end{tabular}

The proposed model is validated herein considering the reported results of a set of triaxial compression tests equalized to $s=300 \mathrm{kPa}$ by Futai and Almeida [17]. A set of drained triaxial compression tests where run with three different confining stresses: 100, 200 and 500 . Table 2 contains the values of the required parameters to input to the model.

Table 2. Input parameters for the proposed model

\begin{tabular}{|c|c|}
\hline Parameter & Parameter value \\
\hline Critical state slope $M$ & 1.14 \\
\hline $\begin{array}{c}\text { Preconsolidation stress in } \\
\text { saturated conditions }\left(p_{0}^{\prime}\right)_{0}\end{array}$ & $100 \mathrm{kPa}$ \\
\hline Shearing Modulus $G$ & $10 \mathrm{MPa}$ \\
\hline Initial void ratio $e$ & 1.18 \\
\hline Compressibility index $\lambda$ & 0.2 \\
\hline Compressibility index $\kappa$ & 0.05 \\
\hline Initial suction of the soil & $300 \mathrm{kPa}$ \\
\hline
\end{tabular}

For the hydraulic part of the model, Table 3 contains the required parameters which arise from fitting the experimental SWCCs [17] to the ones that the model predict. The mean size and standard deviation for both the Solids 1 and the Solids 2 distribution were obtained by fitting the grain-size distribution of the soil to a pair of normal distribution. 1

Table 3. Theoretical Pore-Size distribution of the soil.

\begin{tabular}{|c|c|c|}
\hline & Mean size & Standard deviation \\
\hline Macropores & 10.0 & 2.5 \\
\hline Mesopores & 0.0005 & 3.0 \\
\hline Macrobonds & 8.0 & 4.0 \\
\hline Mesobonds & 0.00001 & 13.0 \\
\hline Solids 1 & 6.0 & 3.5 \\
\hline Solids 2 & 0.0001 & 6.0 \\
\hline
\end{tabular}


The procedure to fit the SWCCs to the model predictions is described elsewhere $[13,18]$.

Once the model parameters are all set up, it is possible to simulate the soil hardening due to suction increase. Initially, the sample is considered as though it where saturated and already in normally consolidated stages. In order to simulate an equalization process up to $300 \mathrm{kPa}$, a drying path must be simulated using the Solid-Porous Model. Initially, all the pores are considered in saturated conditions and suction is increased in steps. With each step, the porous network is all scanned to verify which pores are dry and which ones are saturated; the terms $f^{s}$, $f^{d}, f^{u}, S_{r}^{u}$ and $S_{r}$ are all computed with each step.

Once $s=300 \mathrm{kPa}$ has been reached, the model predicts that the term $\chi=f^{s}+f^{u} S_{r}^{u}=0.63$. Hence, according to Equation (7), the soil effective stress increases as much as $\left(d p^{\prime}\right)_{0 \rightarrow 300}=d(\chi s)_{0 \rightarrow 300}=(0.63) 0.3=0.19$. Therefore, the mean effective preconsolidation stress at $300 \mathrm{kPa}$ will thus be $\left(p_{0}{ }^{\prime}\right)_{0}+2\left(d p_{0}{ }^{\prime}\right)_{0 \rightarrow 300}=0.1+2(0.19)=0.48 \mathrm{kPa}$, and the mean net preconsolidation stress will thus be $\left(p_{0}{ }^{\prime}\right)_{0}+\left(d p_{0}{ }^{\prime}\right)_{0 \rightarrow 300}=0.1+(0.19)=0.29$.

Now, the samples subjected to confining net stresses of 100 and $200 \mathrm{kPa}$ will be in preconsolidated states; a sample subjected to $500 \mathrm{kPa}$ will be in normally consolidated states. The theoretical-experimental result comparisons for the triaxial compression state of these three samples are depicted Figures 4 to 6 .
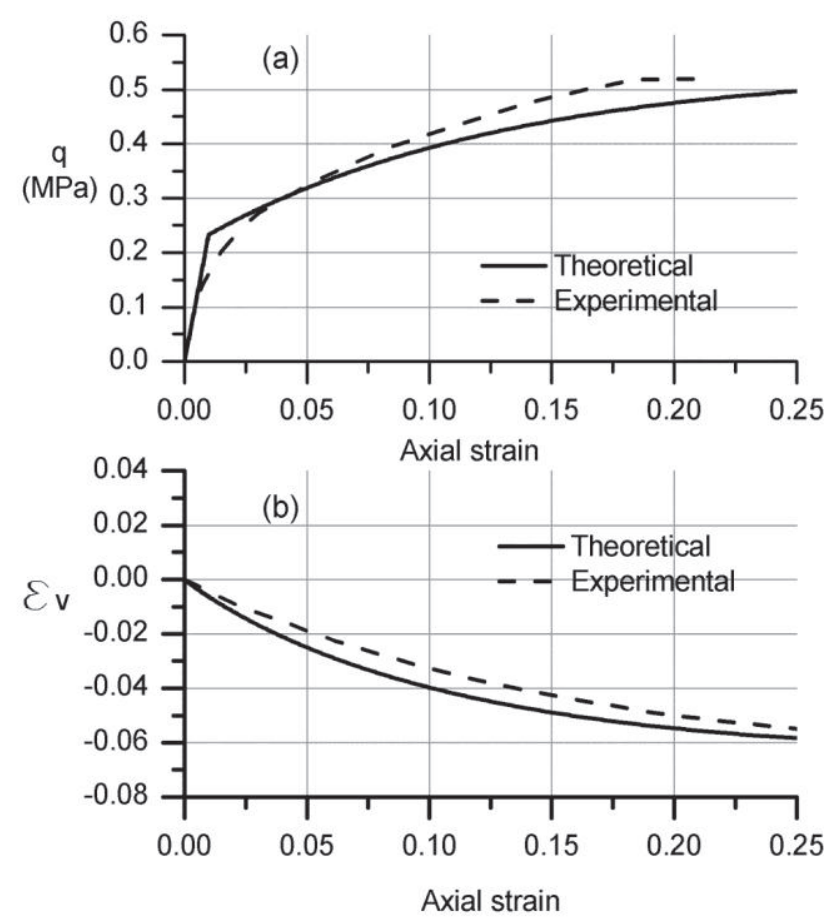

Figure 6 Theoretical-Experimental result comparisons of a soil subjected to a confining net stress $p_{n e t}$ of $100 \mathrm{kPa}$ and suction of $300 \mathrm{kPa}$.

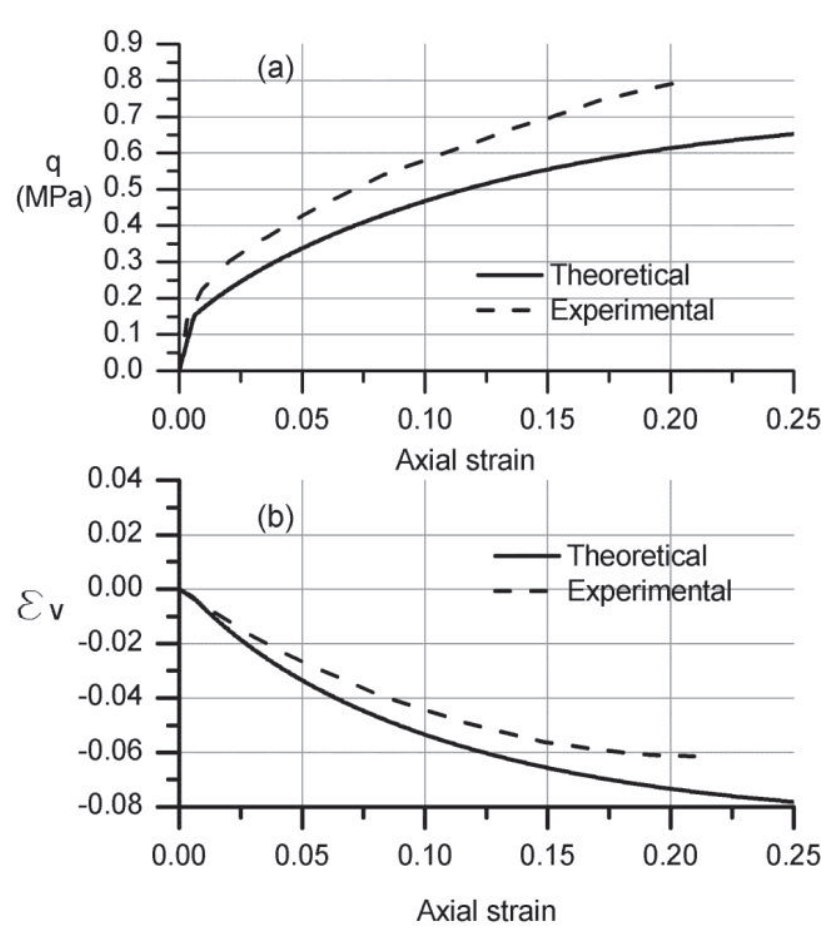

Figure 7 Theoretical-Experimental result comparisons of a soil subjected to a confining net stress $p_{\text {net }}$ of $200 \mathrm{kPa}$ and suction of $300 \mathrm{kPa}$.
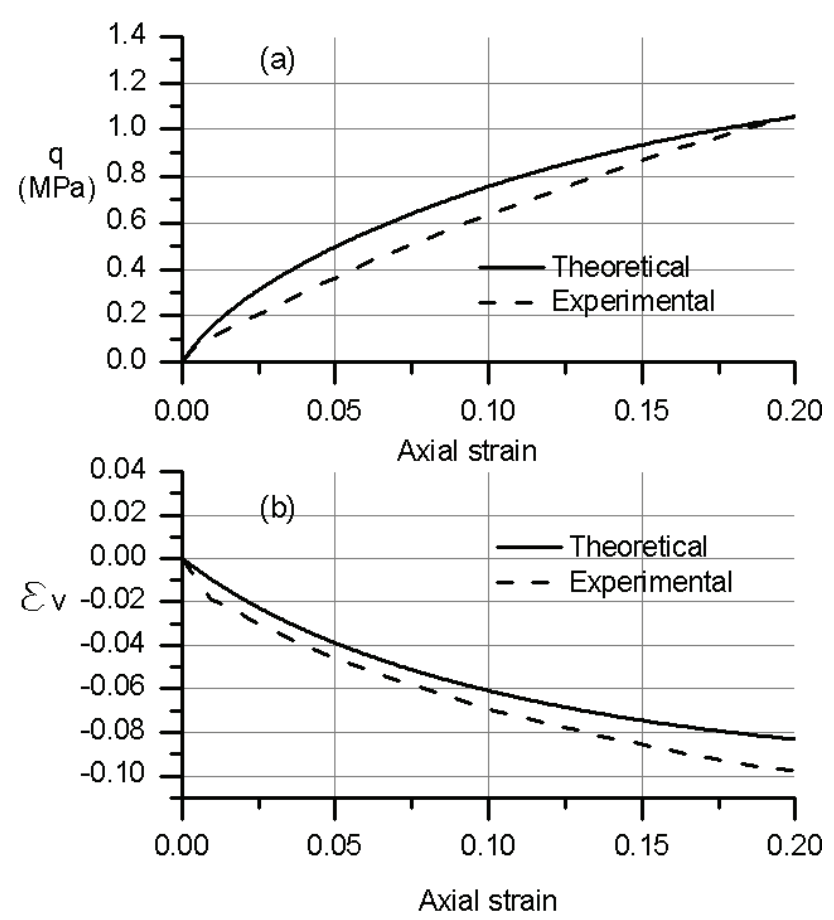

Figure 8 Theoretical-Experimental result comparisons of a soil subjected to a confining net stress $p_{\text {net }}$ of $500 \mathrm{kPa}$ and suction of $300 \mathrm{kPa}$.

Finally, the whole wetting-drying cycle for the expression $\chi=f^{s}+f^{u} S_{r}^{u}$ expressed in terms of the degree of saturation is plotted in Figure 9. From these results, it can be concluded, as reported by several cyclic suction-controlled triaxial tests by Khalili and 
Zargarbashi [19], that despite the assumption $\chi=S_{r}$ provides a first approximation to Bishop's parameter, it is not accurate and will deliver incorrect results. This is far more important when dealing with cyclic loading such as when modeling wetting-drying cycles for slope stability analyses.

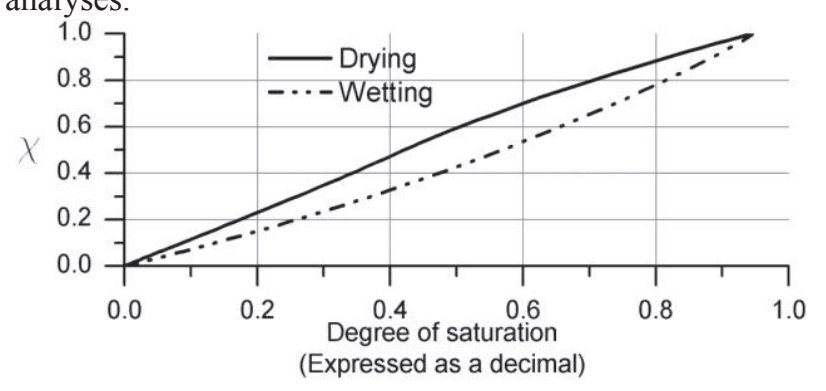

Figure 9 Effective stress parameter $\chi=f^{s}+f^{u} S_{r}^{u}$ for wetting-drying cycles.

\section{Results and discussion}

An elastoplastic model to predict the hardening of a soil under suction increments has been established. The Loading-Collapse yield function in the suction-mean effective stress is derived by considering that the hardening of the soil, equals the contribution to the effective stress due to suction increase. Because the effective stress equation depends on the SWCC through the porous model, the shape of the LC curve will depend on the shape of the SWCC.

The hydraulic and mechanical behaviors are highly coupled. A first approximation to a coupled formulation is achieved in a natural way by using effective stresses on the model formulations where the parameters to obtain such stresses depend on the SWCC. The second approximation to a constitutive model fully coupled model is establishing an equation for the SWCC that considers volume strains. Here, if the soil suffers any volume strain, the hydraulic consequences are that the SWCC displaces towards higher suctions.

The theoretical-experimental result comparisons show that the model is able of predicting the volume strains and axial strains of an unsaturated soil. The model parameters are determined with standard geotechnical tests such as drained triaxial compression tests and isotropic compression states, both in saturated conditions.

\section{References}

[1] E.E. Alonso, A. Gens, A. Josa, A constitutive model for partially saturated soils, Géotechnique 40 (1990) 405 430.

[2] K.H. Roscoe, J.B. Burland, On the generalized stressstrain behavior of 'wet' clay., in: (Eds.), Engineering Plasticity, Cambridge University Press, Cambridge 1968.
[3] M. Nuth, L. Laloui, Effective stress concept in unsaturated soils: Clarification and

validation of a unified framework, Int. J. Numer. Anal. Met. 32 (2008) 771-801.

[4] L. Laloui, M. Nuth, On the use of the generalised effective stress in the constitutive modelling of unsaturated soils, Comput. Geotech. 36 (2009) 20-23.

[5] K. Terzaghi, Erdbaumechanik auf Bodenphysikalischer Grundlage, Franz Deuticke, Leipzig and Vienna, 1925.

[6] D. Sheng, Constitutive modelling of unsaturated soils: discussion of fundamental principles. , in: General Report presented at the 5th International Conference on Unsaturated Soils (6-8 Sept 2010, Barcelona), In: Unsaturated Soils, (EE Alonso \& A Gens, eds), (2010).

[7] B. Loret, N. Khalili, A three-phase model for unsaturated soils, Int. J. Numer. Anal. Met. 24 (2000) 893-927.

[8] Q. Wang, D.E. Pufahl, D.G. Fredlund, A study of critical state on an unsaturated silty soil, Can. Geotech. J. 39 (2002) 213-218.

[9] Y.P. Yao, L. Niu, W.J. Cui, Unified hardening (UH) model for overconsolidated unsaturated soils, Can. Geotech. J. 51 (2014) 810-821.

[10] A.W. Bishop, The principle of effective stress, Teknisk Ukeblad 106 (1959) 859-863.

[11] E. Rojas, Equivalent Stress Equation for Unsaturated Soils. I: Equivalent Stress, International Journal of Geomechanics 8 (2008) 285-290.

[12] E. Rojas, J. Horta, T. López-Lara, J.B. Hernández, A probabilistic solid porous model to determine the shear strength of unsaturated soils, Probabilistic Eng. Mech. 26 (2011).

[13] H. Arroyo, E. Rojas, M.L. Pérez-Rea, J. Horta, J. Arroyo, A porous model to simulate the evolution of the soil-water characteristic curve with volumetric strains, C. R. Mecanique 343 (2015) 264-274.

[14] E. Rojas, M.L. Pérez-Rea, G. Gallegos, J. Leal, A porous model for the interpretation of mercury porosimetry tests, J. Porous Media 15 (2012) 517-530.

[15] J. Horta, E. Rojas, M.L. Pérez-Rea, T. López, J.B. Zaragoza, A random soild-porous model to simulate the retention curves of soils, Int. J. Numer. Anal. Met. 37 (2013).

[16] E. Rojas, M.L. Pérez-Rea, T. López-Lara, J.B. Hernández, J. Horta, Use of Effective Stresses to Model the Collapse upon, J. Geotech. Geoenviron. (2015).

[17] M.M. Futai, M.S.S. Almeida, An experimental investigation of the mechanical behaviour of an unsaturated gneiss residual soil,, Géotechnique 55 (2005) 201-213.

[18] H. Arroyo, E. Rojas, M.L. Pérez-Rea, J. Horta, J. Arroyo, Simulation of the shear strength for unsaturated soils, C. R. Mecanique 341 (2013) 727-742.

[19] N. Khalili, S. Zargarbashi, Influence of hydraulic hysteresis on effective stress in unsaturated soils, Géotechnique 60 (2010) 729-734. 